\title{
¿DISCURSO PORNOGRÁFICO? DIEZ AÑOS DE SEXO EN EL CINE ESPAÑOL (2008-2017)
}

PORNOGRAPHIC DISCOURSE?

TEN YEARS OF SEX IN SPANISH CINEMA (2008-2017)

\author{
Marta Álvarez \\ Université de Bourgogne Franche-Comté (Besançon) \\ marta.alvarez@univ-fcomte.fr \\ LAUREANo MONTERO \\ Université de Bourgogne Franche-Comté (Dijon) \\ laureano.montero@u-bourgogne.fr
}

RESUMEN: El artículo cuestiona la presencia de un discurso pornográfico en el cine español, partiendo de existencia de una tendencia hardcore crossover (Linda Williams) en otras cinematografías. Para ello estudia la representación de las relaciones sexuales en el más reciente cine español, el de los últimos diez años. En esa década asistimos a una confluencia de crisis - la digital, la financiera- que influyen de manera decisiva en las industrias culturales, entre ellas la pornográfi$\mathrm{ca}$, y en la manera de vivir y representar el sexo en el cine generalista.

PALABRAS CLAVE: cine español; sexo; pornografía

ABSTRACT: The article questions the presence of a pornographic discourse in Spanish cinema, from the hardcore crossover trend (Linda Williams) existing in other cinematographies. To do so, it studies the representation of sexual relations in the Spanish cinema of the last ten years. In that decade we notice a confluence of crises -digital, financial- that decisively influence cultural industries, including pornography, as well as the way of experiencing and representing sex in mainstream cinema.

Keywords: Spanish Cinema; Sex; Pornography 
Shortbus (John Cameron Mitchell, 2006), La vie d'Adèle (Abdellatif Kechiche, 2013) o L'inconnu du lac (Alain Guiraudie, 2013) son ejemplos de películas que han causado polémica estos últimos años por lo explícito de sus escenas sexuales. Las tres serían representantes de lo que Linda Williams considera una tendencia del cine contemporáneo, filmes crossover, en los que se cruzan el hardcore y el cine de autor: "filmes con ambición estética, representando relaciones sexuales explícitas y complejas que ni son el punto central del film (como en la pornografía), ni excusas gratuitas (como en el soft core exploitation)" y de los que el cine francés nos habría dado algunos de los ejemplos más vanguardistas (Williams 2009: s.p.). La elaboración de este dosier se cruzó con nuestra curiosidad por esta tendencia, que surge en una época que algunos teóricos califican de pornográfica (Preciado 2013; Attimonelli y Susca 2017) y que nos ha llevado a una reflexión más amplia acerca de la representación de la sexualidad en el cine español actual, animándonos a plantearnos si este vehicula un discurso pornográfico o no.

Algún artículo publicado en este dosier y en otros lugares (Ares y Pedraz Poza 2011) muestra que sí: existe un discurso pornográfico más allá de la pornografía industrial, reconocible en una pornografía alternativa encarnada por autoras como Erika Lust o Lucía Egaña y que invita a la representación de otros cuerpos y prácticas más allá de la mirada androcéntrica y heterosexual dominante. El documental Yes, we fuck (Antonio Centeno y Raúl de la Morena, 2015) es sin duda otro excelente ejemplo de lo que podemos considerar una militancia audiovisual, por extender el dominio de lo representable, multiplicar voces y miradas.

Hemos creído de interés contribuir con un trabajo que cuestione en este sentido un cine que podemos considerar generalista, en cuanto se dirige a audiencias (más o menos) amplias a través de estrategias de distribución y exhibición normalizadas dentro de la industria: estreno en sala, festivales de cine y plataformas de vídeo bajo demanda. Partir de un amplio marco nos permitirá ofrecer un esbozo de panorámica de la representación de las relaciones sexuales en el más reciente cine español y avanzar si esa supuesta "pornografización" de la sociedad se ha adueñado, efectivamente, de las pantallas.

Nuestro estudio se concentra en la producción cinematográfica de esta última década. Nos hemos limitado en el tiempo para poder visionar una cantidad significativa de filmes; por otra parte, estos últimos diez años destacan de manera particular por una serie de circunstancias socio-económicas y culturales específicas. En efecto, la crisis financiera que estalló en 2007 vino a cruzarse con los efectos de otras crisis, como las que afectaron a las diferentes industrias culturales por causa del giro digital, y a determinar nuevas prioridades en las pantallas, como no dejaremos de señalar.

\footnotetext{
1 Paul B. Preciado considera que "las industrias líderes del capitalismo postfordista, junto con la empresa global de la guerra, son la industria farmacéutica [...] y la industria pornográfica" (2013: 37). Según el autor, el "farmacopornismo" habría sustituido al fordismo anterior (2013: 25-45). Claudia Attimonelli y Vincenzo Susa utilizan, por su parte, el término "pornocultura", para designar el ambiente pornográfico generalizado en el que nos hallaríamos inmersos (2017: 16).
} 
Comenzaremos nuestra aproximación al tema definiendo las premisas de las que partimos -¿qué entendemos por discurso pornográfico?-, para ofrecer a continuación algunas reflexiones acerca de la representación del sexo en el cine español de los últimos diez años. Nos interesará cuestionar si las películas en las que la representación de la sexualidad es más explícita pueden equipararse con esa modalidad crossover a la que nos referíamos al comienzo de estas líneas, antes de detenernos, para terminar, en aquellas que tematizan la industria pornográfica.

\section{1. ¿DISCURSO PORNOGRÁFICO?}

En 2011, Francisco García García y Miguel Arroyo Fernández coordinaron un monográfico sobre "Discursos de la sexualidad en el cine". Comienzan la presentación de esas páginas con una aclaración de lo que los coordinadores entienden por "discurso": el término, en narrativa audiovisual, se distingue de la 'historia' -lo que se cuenta-, pues designa el "cómo se cuenta" (García García y Arroyo Fernández 2011: 1)-. Esta acepción se cruza con:

... el concepto filosófico de "discurso" tal como lo empleó, entre otros, Foucault (1977). En suma, nos interesaban tanto las técnicas que emplea el lenguaje cinematográfico para representar la sexualidad, como la "lucha de discursos" -los distintos puntos de vista ideológicos y morales que el cine transmite acerca de la sexualidad humana- y los procesos de cambio social e ideológico en los que el cine participa. (García García y Arroyo Fernández 2011: 2)

De la misma manera, si pretendemos poner de manifiesto en estas páginas las estrategias fílmicas que sirven de modo de expresión, entendemos que son determinantes los valores que las deciden. El "carácter instituyente del cine, como creador de valores y significados" que resalta José Miguel Viña (2011), es hoy en día bien discutible, en lo que concierne a un cine español que se enfrenta a industrias hegemónicas, como la estadounidense, y a una multiplicación de pantallas que ha modificado las reglas de la influencia cultural. En todo caso, seguimos encontrando en los filmes un reflejo de los usos amatorios de las sociedades que los crean y de sus evoluciones.

Es de constatar la relativa escasez de bibliografía sobre el tema. No son muchos los libros escritos por investigadores españoles, y se trata de estudios que abordan la cuestión sin limitarse a la cinematografía nacional. Se da, además, una especie de paradoja, pues si los estudios sobre sexo y cine destacan la escasa visibilidad de las sexualidades no hegemónicas, la cantidad de volúmenes publicados en este joven siglo sobre cine y homosexualidad (García Rodríguez 2008; Mira 2008; Cristobal 2010; Melero Salvador 2010; Palencia 2011) parece más numerosa que la de aquellos que tratan de manera general cuestiones sexuales (Freixas y Bassa 2000; Barroso 2001; Freixas y Bassa 2005). Claro que habría que completar esta bibliografía con otros trabajos, incluidos en volúmenes 
colectivos o en dosieres como el de Icono 14, al que hemos hecho referencia, o el más reciente "Sexo y erotismo en el cine" (Pavés y García Gómez 2017). ${ }^{2}$

Sexo, erotismo... ¿y lo pornográfico? Nos hemos resistido a tratar la cuestión de manera frontal por cierta querencia a subrayar lo poroso de las fronteras, sobre todo cuando estas se contemplan con distancia histórica. No nos atrevemos sin embargo a limitarnos al consabido "la pornografía de hoy es el erotismo de mañana"3 por ser la pornográfica una industria audiovisual identificable que genera un importante volumen de negocio y que ha dado lugar a un género cinematográfico particular e incluso a un campo de estudios que empieza a desarrollarse en Europa. ${ }^{4}$ En efecto, en el área que nos concierne, la importancia del trabajo fundador de Linda Williams $(1989,2004)$ es reseñada y tomada como punto de partida de propuestas como la de Álex Mendíbil Blanco, Francisco García García y María Luisa García Guardia (2017), en "Narratología porno. Una lectura semiótica de Tras la puerta verde", un artículo que propone "una lectura que privilegie el análisis narrativo de las escenas pornográficas sobre las no pornográficas, y que pudiera ser transversal e inclusivo, aplicable a cualquier época y formato de pornografía ya sea cine, video, escena o retransmisión desde una webcam" (157). No es baladí la enumeración de medios, formatos y dispositivos, pues los autores son bien conscientes de la evolución de las formas audiovisuales pornográficas, desde los primeros stag films -pequeñas películas donde un grupo pequeño de personas practicaban sexo ante la cámara, sin apenas necesidad de situación dramática" (Mendíbil, García García y García Guardia 2017: 158) - hasta los tubes actuales - secuencias de contenido pornográfico que inundan Internet y que, como los antiguos filmes, se ven libres de integración en una estructura narrativa mayor-, pasando por los largometrajes pornográficos, que, según los investigadores, "se podrían considerar ya una excepción, una anomalía en la historia de la producción audiovisual pornográfica" (156).

Insisten, quienes analizan el género pornográfico, en lo codificado de su lenguaje (Williams 1989, Gubern 2005, Servois 2009). La representación de actos sexuales explícitos se considera como característica del género, que Román Gubern define con respecto a otras formas cinematográficas: "empieza allí donde se inicia el fundido y se interesa específicamente por esas omisiones pasionales propias del cine tradicional" (Gubern 2009: 22). Con respecto a este, el cine

\footnotetext{
2 Se trata simplemente de aportar algún indicador significativo, pues, por supuesto, habría que tener en cuenta igualmente los artículos dispersos en otras revistas y libros para establecer una bibliografía exhaustiva.

3 Prada (2009: s.p.) recoge la frase en un artículo en el que afirma su imposibilidad para distinguir claramente entre erotismo y pornografía. En el mismo sentido, ha terminado pasando a la historia la afirmación "Sé lo que es cuando lo veo", con la que el magistrado Potter Stewart en 1964 expresaba su dificultad para definir la pornografía (García 2009: s.p.).

${ }^{4}$ En Francia, país en el que trabajamos, ha sido sobre todo decisiva la labor de Marie-Anne Paveau (2014) -ver también Paveau y Perea (2015)-, quien reivindica los trabajos de Williams y reconoce la necesidad de ofrecer un análisis textual del corpus pornográfico, pero hay que considerar asimismo trabajos sobre pornografía en otros ámbitos, como los de Ruwen Ogien (2008) o Michela Marzano (2003b), que desde la filosofía y el feminismo (antisexo) abordan las dimensiones morales y sociales del hecho pornográfico.
} 
pornográfico "duro" ejercería una "estricta selectividad monotemática", además de "trasgredir los tabúes iconográficos tradicionales en el medio, anatemizados por su hiperrealismo anatómico y fisiológico" (22-23). Se crea así una estructura dual (entre escenas narrativas y sexuales) que lleva a Linda Williams a subrayar el carácter espectacular del acto sexual en este tipo de cine y a realizar un paralelismo entre cine pornográfico y cine musical, aspectos que Jean Servois (2009) corrobora años después y que siguen siendo de utilidad para los investigadores que se van atreviendo a analizar un corpus tan estigmatizado. ${ }^{5}$

Nuestro objeto de estudio no es la producción pornográfica industrial sino la producción cinematográfica generalista que se distribuye en circuitos de cine comercial y de festival. Esta se deja contagiar por los modos de expresión de la primera ${ }^{6}$ y tematiza en ocasiones la propia industria pornográfica, como no dejaremos de ver. ¿Qué rasgos identifican ese "contagio" y definen la presencia de un discurso pornográfico en el cine generalista? Siguiendo a los autores que hemos citado, entendemos que el discurso pornográfico se traduce en primera instancia en la eliminación de las barreras impuestas tradicionalmente a la pulsión escópica del espectador, en el acceso visual directo a la desnudez de los cuerpos y a su actividad sexual. Esa visibilidad es un elemento esencial en nuestro cuestionamiento de los filmes de estos últimos diez años, aunque también nos interesa, como hemos avanzado, la tematización de lo pornográfico. Dedicaremos ahora algunas páginas a realizar un recorrido por las representaciones sexuales que nos ofrecen las películas de la última década. Ello nos permitirá tener ya una primera impresión acerca del grado de pornografización general de las pantallas españolas.

\section{DE NORMAS LIBIDINALES}

En 2013, El blog de cine español elaboraba un ranquin de las películas españolas más eróticas del siglo xxı. Diez filmes ${ }^{7}$ entran en una lista que viene precedida por unas palabras un tanto descorazonadoras: "como ocurre en la vida misma, en nuestro cine hay menos sexo del que nos gustaría" (El blog de cine español 2013). Tres años después Cinemanía cierra el artículo: “¿Hay un lugar para el erotismo en el cine?" con parecido desaliento: "Sí, el futuro es desolador. Habrá que

\footnotetext{
${ }^{5}$ Contrariamente al dosier de Icono 14, el de la revista Fotocinema contiene algún artículo que analiza obras exhibidas en los circuitos de la pornografía industrial, como Behind the Green Door (Artie Mitchell y Jim Mitchell, 1972) -un "clásico" del género que estudia asimismo Julien Servois (2009) - o los filmes de Michael Ninn (Mendíbil Blanco, García García y García Guardia 2017; Fuentefría Rodríguez 2017).

${ }^{6}$ La mayoría de la bibliografía que manejamos señala esos cruces y coincide en dar como ejemplos tempranos filmes como Last Tango in Paris (Bernardo Bertolucci, 1972) o El imperio de los sentidos (Nagisa Oshima, 1976).

7 Serían, del décimo al primer puesto según la clasificación del sitio: Son de mar (Bigas Luna, 2001), Mapa de los sonidos de Tokio (Isabel Coixet, 2009), Torremolinos 73 (Pablo Berger, 2002), Amor idiota (Ventura Pons, 2005), El sexo de los ángeles (Xavier Villaverde, 2011), Cachorro (Miguel Albaladejo, 2004), El cónsul de Sodoma (Sigfrid Monleón, 2010), Habitación en Roma (Julio Médem, 2010), Mentiras y gordas (David Menkes y Alfonso Albacete, 2009) y Lucía y el sexo (Julio Médem, 2001).
} 
volver a los vídeoclubs y alquilar Emmanuelle" (Moral 2016: s.p.). La razón estaría en el desplazamiento del sexo a Internet: "con todos los seres humanos a un clic de dar rienda suelta a sus perversiones sexuales en la más absoluta intimidad ¿a quién le pueden interesar las películas pretendidamente eróticas?" (Moral 2016: s.p.). ¿Para qué mostrar? El espectador del siglo xxı lo habría visto ya (casi) todo, y tiene acceso en todo momento y lugar a cualquier imagen. En 2015, esas eran las razones invocadas por los dirigentes de Playboy para eliminar los desnudos integrales de sus páginas (El Mundo 2015), aunque dos años después la revista los recupera en su interior, el trabajo de disimulo de algunas portadas no deja de llamar la atención de otros medios que asisten a esta transformación (El País 2017). ¿Produce de la misma manera el auge de la pornografía en Internet un recato en el cine más reciente y más particularmente en el español, que aquí nos interesa? El siglo había sin embargo comenzado con una película de gran intensidad sexual: Lucía y el sexo (Julio Médem, 2001), film que tal vez podamos proponer como ejemplo de hardcore de autor (Williams 2009: s.p.), como muestra de esa alianza entre erotismo e ideas (Moral 2016: s.p.) que se daría en los años 2000.

No faltaba mucho para que otra crisis viniera a trastornar la vida de los españoles, y a iniciar la década que aquí nos interesa. ¿Podemos poner en relación las circunstancias socio-económicas con cierta deserotización de las pantallas? En el "cine de la crisis" (Albritton 2014; Kourelou, Liz y Vidal 2014) o "cine de la austeridad" (Villarmea Álvarez 2016) la vida sentimental y sexual de los personajes pasa a un segundo plano ante otras preocupaciones: la búsqueda de trabajo, cuando no la simple lucha por la supervivencia. Los lazos afectivos privilegiados son los filiales, y estos se tiñen de continua preocupación, cuando no de angustia -Techo y comida (Juan Miguel del Castillo, 2015), El triste olor de la carne (Cristóbal Arteaga, 2013). Las relaciones sexuales se plantean en varios filmes como fuente de monetarización -Hermosa juventud (Jaime Rosales, 2014), Magical Girl (Carlos Vermut, 2014), A puerta fría (Xavi Puebla, 2012), Murieron por encima de sus posibilidades (Isaki Lacuesta, 2014), Cerca de tu casa (Eduard Cortés, 2016).

Resulta difícil practicar sexo cuando ni siquiera se posee un espacio propio: varios filmes denuncian la ausencia de privacidad provocada por la crisis, que obliga en ocasiones al regreso a la casa de los padres -Cinco metros cuadrados (Max Lemcke, 2011), Cerca de tu casa- y que lleva a veces a la muerte-Ayer no termina nunca (Isabel Coixet, 2013), Murieron por encima de sus posibilidades (Isaki Lacuesta, 2014). La crisis separa los cuerpos: por lo que hemos dicho hasta ahora pero también por la distancia que impone a aquellos personajes que ven la emigración como la única oportunidad de encontrar una salida laboral -Hermosa juventud, Perdiendo el Norte (Nacho G. Velilla, 2015)-. Si en Perdiendo el norte el molde de la comedia romántica exige la formación de nuevas parejas y permite flirteos con el vodevil, otras películas insisten en la complejidad y el sufrimiento que supone el alejamiento. En 10000 kilómetros (Carlos MarquesMarcet, 2014) son los Estados Unidos el lugar que ofrece a Álex (Natalia Tena) una gran oportunidad que no se le hubiera presentado en España. La joven fotógrafa realizará su sueño profesional pero tendrá para ello que sacrificar la 
relación que había construido con Sergi (David Verdaguer). El film se abre con los gemidos de ambos practicando sexo: es evidente su satisfacción y complicidad durante los siete minutos en los que vemos a los personajes hablarse, abrazarse, besarse en un plano medio que se irá cerrando y que ocupan íntegramente... como no volverán a hacerlo. En efecto, desde sus residencias respectivas en Barcelona y en Los Ángeles, las redes sociales y programas y aplicaciones diversas funcionarán como fríos simulacros del contacto físico. ${ }^{8}$ De hecho, la dificultad de practicar cibersexo pone en evidencia que la distancia que existe entre ellos ya no es solo física. ${ }^{9}$

Las películas a las que nos hemos referido, bien paradigmáticas del cine de la crisis, sin prestar gran atención a la -dificultada- vida sentimental y sexual de los personajes, dibujan en esos ámbitos unas constelaciones más bien tradicionales. Las parejas y las familias heterosexuales son el horizonte al que tienden unos personajes que podríamos calificar de conservadores, en tanto en cuanto lamentan la imposibilidad de responder al modelo para el que la misma sociedad que se lo niega los había formateado. Sin embargo, esa imagen no engloba la totalidad de los usos amatorios que proponen (¿e imponen?) las pantallas españolas, que dan cabida a productos bien diversos. Las adaptaciones de best-sellers internacionales, por ejemplo, se cristalizan en filmes juveniles que definen un star system igualmente juvenil que va integrándose conforme avanza la década en otros ámbitos de la industria cinematográfica (Mario Casas, María Valverde, Clara Lago.... $)^{10}$ y que resultan de particular interés por ser el espejo en el que van a intentar identificarse las más jóvenes generaciones. Estos filmes comparten éxito de audiencia con thrillers y películas de terror, pero también con dramas y comedias cuyos temas y motivos de peso, cuando no los pilares de la trama, son el amor y el sexo.

En torno a esas cuestiones, el cine más contemporáneo nos muestra que, dentro de cierto tradicionalismo, algunos parámetros han cambiado claramente. Creemos que sigue siendo válida la afirmación de José Manuel Viña, quien nos recuerda que "[l]a representación de las prácticas sexuales en el ámbito ficcional de la cinematografía ha derivado en la consolidación de valores y prejuicios instituidos como marco normativo, excluyente para con determinadas tendencias", hacia las cuales el cine aplicaría un "tratamiento discursivo pesimista y reaccio-

8 El film de Jaime Rosales fusiona pantallas, tipos de imágenes y texturas, pero es sin duda en este sentido 10000 kilómetros más interesante, al centrarse en la pareja y en una relación que se desarrollará a distancia durante la mayor parte del film (Villarmea Álvarez 2016).

9 No hay sin embargo mucho cibersexo en el film, como tampoco en general en la producción cinematográfica española. Encontramos otro ejemplo en Buscando el norte (Atresmedia, Antena 3, 2016, 00:6:33m 1x02), la versión en serie de la comedia sobre la emigración. Resulta interesante comparar las muy diferentes escenas en las dos obras, las representaciones y significados son deudores de los casi opuestos medios y estilos. El realismo cibernético, la verosimilitud y profundidad en el tratamiento de los personajes del film contrasta con la ligereza de la sitcom.

10 En este sentido hay que subrayar también la labor de algunos realizadores, que acompañan a estas estrellas, es el caso de Fernando González Molina, a quien se debe la adaptación de las novelas de Federico Moccia y otros filmes de gran popularidad: Fuga de cerebros (2009), Tres metros sobre el cielo (2010), Fuga de cerebros 2 (2011), Tengo ganas de ti (2012), Palmeras en la nieve (2014) y El guardián invisible (2017). 
nario" (2011: 178). Lo que sucede es que ese marco normativo ha evolucionado con respecto al que imperaba en las épocas en las que se producen las obras que estudia el crítico -todas del siglo xx. En el siglo xxI, el mito del amor romántico se erosiona ante la relatividad de la exclusividad sexual y la desaparición de la importancia de la virginidad, temas encarnados por personajes femeninos que no ven mayor problema en multiplicar las experiencias sexuales, favoreciendo la representación de la cópula con fines meramente recreativos, lo que se opone a modelos anteriores (Freixas y Bass 2005: 49; Viña 2011: 179).

La pareja heterosexual sigue siendo la modalidad dominante, pero no son raros los personajes homosexuales. En algún film, como Mentiras y gordas (David Menkes y Alfonso Albacete, 2009), algún personaje parece todavía encarnar la "tragedia y destrucción" que acompañan al "alzarse contra la sexualidad normalizada" (Viña 2011: 179) -el personaje de Toni (Mario Casas) convertido en víctima expiatoria-, pero la representación de otros personajes homosexuales en el mismo film impide llegar a conclusiones tajantes a ese respecto, ${ }^{11}$ favoreciendo, al contrario, la impresión de que la intención es anular los estigmas que pesaban (y todavía pesan) contra ciertas prácticas sexuales. Más allá de la presencia y variedad de personajes homosexuales, ${ }^{12}$ querríamos llamar la atención acerca de figuras que se caracterizan por una apertura y/o curiosidad que plantea la orientación sexual como opción y que lleva en ocasiones a proponer diferentes modelos de convivencia: El sexo de los ángeles (Xavier Villaverde, 2012) y Kiki, el amor se hace (Paco León, 2016) son buenos ejemplos, al cerrarse ambos filmes con la confirmación (celebración, más bien) del trío como comunidad amorosa (dos chicos y una chica en El sexo de los ángeles, dos mujeres y un hombre en Kiki), para la cual no es obstáculo la presencia de una hija, como sucede en el film de Paco León. Puede objetarse a este respecto la escasa problematización de lo que supone esta particular forma de convivencia, sobre todo en el último film, pero creemos que en esa circunstancia se encuentra la sanción positiva del modelo, así como en otros filmes el final con boda entre la pareja heterosexual se entiende como afirmación de ciertos valores. Resulta en este sentido útil contrastar las películas que acabamos de mencionar con otras propuestas

\footnotetext{
11 Incluso la del propio Toni: Alfeo, González de Garay y Rosado señalan lo "sorprendente" del contraste entre la construcción del personaje y "el final autodestructivo al que se ve abocado" (2011: 46).

12 Encontramos en los filmes personajes con caracteres y destinos variados: homosexuales "con pluma" (Los amantes pasajeros), sin ella (Barcelona, noche de verano), bisexuales (El sexo de los ángeles), heterosexuales que se dejan tentar (Habitación en Roma), personajes que no se plantean la cuestión (La propera pell, Isaki Lacuesta e Isa Campo, 2016) y otros que realizan un comming out tardío, como la abuela de Barcelona, noche de verano. Ramiro Cristobal cree que "el cine va hoy muy por delante de la evolución de las conciencias. El rechazo mayoritario a los homosexuales no se corresponde con la aceptación que existe de la temática gay ya en el cine" (2010: 8-9). Sería sin embargo arriesgado hablar de una "normalización" en estas cuestiones, ver al respecto las páginas que Alberto Mira dedica a "esa 'normalización' tan escurridiza" (2008: 519-525). En lo que se refiere al contexto español, podemos sin embargo afirmar que ya no nos encontramos en aquellas épocas en las que la "identidad gay en el cine fue [...] una quimera; su reivindicación, improbable" (Freixas y Bassa 2005: 248). Ver también Alfeo, González de Garay y Rosado y su estudio sobre la "Adolescencia LGBT en el cine español", en particular las páginas dedicadas a "Nuevos tiempos, nuevos modelos" (34-47).
} 
en celuloide que tratan la cuestión del trío, como la clásica Jules et Jim (François Truffaut, 1962), la cual presentaría:

... una contradicción discursiva, al generar expectativas sobre una nueva forma de sentir y vivir las relaciones (ideal, utópica...) y denegar su concreción física (la expectativa es irrealizable). De nuevo, el código de la monogamia heterosexual se impone, saldándose con la ejecución/soledad de los insumisos. (Viña 2011: 187-188)

Irrealizable se descubre la convivencia entre los tres personajes de Castillos de cartón (Salvador García Ruiz, 2009). Lejos de la fluidez de las películas arriba mencionadas, sobre este trío pesan sospechas y amenazas desde su constitución. Esta se debe, de hecho, al disfuncionamiento eréctil de Marcos (Nilo Mur), que hace que Jaime (Biel Durán) entre en juego para satisfacer a María José (Adriana Ugarte) (00:11:50): no deja de extrañar esa fijación con la penetración, cuando el cine de los millenials, aunque representándola como dominante dentro del repertorio, va ampliando su espectro de prácticas sexuales. Castillos de cartón resulta un tanto anacrónico en este sentido, tal vez no sea ajeno a esta circunstancia el hecho de que se trate de una adaptación de la novela de Almudena Grandes (2004), y que la acción se sitúe en los años ochenta. En efecto, el visionado del film nos hace pensar más en la producción cinematográfica de décadas anteriores. El miedo a la homosexualidad de Jaime y la sospecha acerca de la homosexualidad de Marcos no se disolverán sino que vendrán a reforzar la rivalidad que se crea entre los personajes y que decreta el fin del trío. La sinopsis del film resume bien la función del grupo, que se presenta como experiencia de paso y formación previa a la entrada en la vida adulta, cuando "deban enfrentarse al mundo real" (Filmaffinity, el subrayado es nuestro). El cine de esta última década nos indica, sin embargo, que ese "mundo real" ha cambiado, y que se van normalizando otras convenciones amatorias y sexuales.

La comedia romántica, género que nunca falta en cualquier lista de las películas preferidas en las diferentes cinematografías, resulta un barómetro bastante fiable para constatar la evolución de esas convenciones. Nos interesan a este respecto las reflexiones de Eloy Fernández Porta, quien lee la "normativa libidinal" de nuestra época a través de Foucault y Preciado, y del análisis que ciertas corrientes de los estudios culturales han realizado del lenguaje mediático. Estaríamos viviendo en "la era del mercado afectivo", en la que:

A diferencia de épocas anteriores, donde el régimen de legislación libidinal se expresaba por medio de la cooperación entre las instancias penales, religiosas y policiales, [...] este contenido normativo fue objetivado en fuentes de difusión no coactivas, "de libre albedrío", como los media o la literatura popular ... (Fernández Porta 2012: 73)

El ensayista entiende que en ese contexto la comedia romántica actúa como "género de carácter reglamentarista-pedagógico" que consigna "los cambios recientes en las costumbres libidinales de la época, y las últimas incorpo- 
raciones a sus códigos" (74), reflejando su estructura la fase de negociación necesaria y diferenciando al fin entre "los comportamientos regularizados y los excéntricos" (74).

Kiki, el amor se hace; Tensión sexual no resuelta (Miguel Ángel Lamata, 2010), Barcelona, noche de verano y Barcelona, noche de invierno (Dani de la Orden, 2013), Tres bodas de más (Javier Ruiz Caldera, 2013), Perdiendo el norte (Nacho G. Velilla, 2015), Ahora o nunca (María Ripoll, 2015) o Tenemos que hablar (David Serrano, 2016), ${ }^{13}$ son solo algunos ejemplos de filmes que responden a ese "modelo narrativo universal" (Fernández Porta 2012: 75) en el que se encarnarían los nuevos usos amorosos: la homosexualidad se contempla como una variante (que debería estar) normalizada, los roles de género son (en ocasiones) menos estereotipados, el trío se presenta como una opción a la pareja y la boda... como una costumbre social que no se conjuga fácilmente con el amor y que se celebra en ocasiones para atreverse a decir no ante el altar (Perdiendo el norte) o para que los novios se declaren su mutuo desamor antes de elegir nuevas parejas (Tensión sexual no resuelta). Sin duda el humor y la ligereza que caracterizan el género permiten que se traten unos temas que resultarían más espinosos en el molde del realismo social, pero creemos que esa aparente libertad, conjugada con el carácter pedagógico al que acabamos de hacer referencia, confiere a esta modalidad cinematográfica un innegable interés en las cuestiones que aquí nos preocupan.

\section{3. ¿Cuestión de encuadre?}

Los filmes dan cuenta, pues, de una liberalización de los usos amorosos y sexuales, pero cuanto más se liberan los personajes en cuestiones libidinales, menos sexo se muestra en las pantallas. En efecto, si algunas escenas de contenido erótico salpican los filmes que hemos visionado, la mayoría es poco explícita y remite a una iconografía que nos resulta familiar: se sigue privilegiando el desnudo del busto femenino y una representación de la penetración que excluye la visión de los genitales. Pero también encontramos nuevas imágenes, que reflejan los cambios que hemos comentado. Así, por ejemplo, si el desnudo masculino es rastreable en el cine español en diferentes épocas, parece estar perdiendo hoy las connotaciones de marginalidad y excepción que en otros momentos se le otorgaba, ${ }^{14}$ pues lo encontramos en películas de gran público y juveniles (Mentiras y gordas, El sexo de los ángeles) junto con otros filmes en los que no existe una problematización particular sobre cuestiones de representación sexual (10000 $\mathrm{Km}$ ). Asimismo, es llamativa la transformación del rol femenino. Sin duda, la incorporación de cineastas mujeres es en parte responsable de la inclusión de personajes menos estereotipados, pero el porcentaje de directoras sigue siendo tan

\footnotetext{
${ }^{13}$ Este último film, al igual que el de Nacho G. Velilla, al que ya hemos referencia, podría considerarse además como cine de la crisis, ya que las situaciones de los personajes se encuentran directamente determinadas por la coyuntura.

${ }^{14}$ Como en los filmes de Eloy de la Iglesia, en los que aparece con un claro sentido reivindicativo, como hemos estudiado en otro trabajo (Montero 2014).
} 
escaso ${ }^{15}$ que no podemos achacar la transformación a dicha circunstancia. Nos atrevemos en cambio a proponer una extensión de la mirada femenina, patente en filmes que contradicen modelos patriarcales, al mostrar a mujeres que toman la iniciativa -presentes en la mayor parte de los filmes que hemos citado-, pero también a hombres preocupados por la satisfacción sexual de su pareja. ${ }^{16}$ En este sentido es llamativa la representación del cunilingus -El sexo de los ángeles, Mentiras y gordas, Mapa de los sonidos de Tokio-: podemos calificarla de discreta, estamos lejos de la "visibilidad óptima" que Román Gubern (2009: 19) postula para el cine pornográfico, pero vamos hacia la normalización de ese gesto que supone que sea ella quien tenga una cabeza entre las piernas.

No pretendemos dar un valor general a estas consideraciones, que seguramente no resistirían un estudio en profundidad orientado con la variante de género y suficientemente dotado en estadísticas, ${ }^{17}$ creemos sin embargo que la presencia y recurrencia de estas nuevas figuras es ya reseñable y marca un cambio importante. ${ }^{18}$ Seguimos sin embargo constatando que esa transformación y variedad de prácticas no se traduce en una representación explícita; de hecho, resulta muy revelador que la elipsis sea una figura privilegiada para narrar los encuentros sexuales. En este sentido, querríamos detenernos en varios ejemplos particularmente representativos, por la importancia que cobra en ellos la cosa sexual.

Los protagonistas de Hermosa juventud participan en un rodaje pornográfico, del que veremos el antes y el después, elidiéndose del metraje casi la totalidad del film intradiegético. En Tres bodas de más asistimos a varios desconcertados despertares de la protagonista, quien no recuerda nada de sus aventuras sexuales nocturnas. Solo la situación -la vemos acompañada en la cama- y los comentarios de otros personajes nos permitirán comprender qué ha sucedido.

Es tal vez Stockholm (Rodrigo Sorogoyen, 2013) la película más elocuente en este sentido, pues todo gira en torno al encuentro sexual de los protagonistas, momento que sirve de cesura principal, que estructura y modifica el sentido del film... y que nos es totalmente escamoteado. Si ciertos elementos perturban una lectura unívoca de la película, ${ }^{19}$ es evidente la voluntad de concentrarse en la representación de los juegos de poder que rodean el acto sexual, así como en

\footnotetext{
15 Las cifras sobre el porcentanje de realizadoras en España se hallaría entre un $16 \%$ y un $20 \%$ (CIMA 2017, Del Corral 2017), lo cual resulta elevado con respecto al escaso $8 \%$ que señalaba en 2010 Fátima Arranz (24), pero sin duda se halla todavía muy lejos del porcentaje de filmes realizado por varones.

${ }^{16}$ En 10000 kms, Sergio (David Verdaguer) pregunta directamente a Álex (Natalia Tena) si quiere que siga tras saberse él satisfecho (00:03:25), en Kiki, el amor se hace, el personaje que interpreta Paco León entiende las necesidades bisexuales de su compañera, lo que llevará a la formación del trío. No podemos dejar de mencionar que este film resulta controvertido, al incluir asimismo la realización de las fantasías eróticas de José Luis (Luis Bermejo), quien droga para ello sin su consentimiento a su esposa Paloma (Mari Paz Sayago).

17 Como el que realizó Pilar Aguilar para las películas de la primera década del siglo XXI (2010).

18 Ver el libro de Pilar Aguilar Carrasco (1998), el cual, interesándose por la imagen de la mujer, estudia la representación del sexo en el cine español de los años 90.

19 Las referencias a la inestabilidad emocional del personaje interpretado por Aura Garrido.
} 
el carácter genérico de la hegemonía sexual. La joven misteriosa que, pese a su resistencia inicial, termina "cayendo en la trampa" de quien no quiere entender todavía que un no es un no, parece venir a recordarnos que, pese a los cambios aparentes, los tradicionales roles de poder erótico-sentimental siguen estando vigentes.

En estos y en otros filmes, pues, el sexo se practica, de sexo se habla, pero no se le da lugar en el plano y si se halla presente en él, el encuadre se encarga de evacuar las imágenes más explícitas. Alguna producción de este mismo año confirma lo que acabamos de exponer: Como la espuma (Roberto Pérez Toledo, 2017) resulta ilustrativa a este respecto, ya que la unidad temporal en la que se concentra el film se corresponde con la celebración de una fiesta de cumpleaños muy particular: una orgía. Como en Eyes wide shut (Stanley Kubrick, 1999) o Shortbus (John Cameron Mitchell, 2006) -aunque sin la misma profundidad ni gravedad-, encontramos aquí un cuestionamiento de los modelos sentimentales y sexuales hegemónicos, pero llama la atención el contraste entre la carnalidad de los dos filmes estadounidenses, sobre todo del de Cameron Mitchell, y el pudor de la película de Pérez Toledo, cuyos personajes son mostrados en la casi totalidad de los planos - muy pocos incluyen parciales y fugaces desnudos- en traje de baño o en ropa interior, quedando fuera de cuadro aquellas partes que se saben sin ropa.

Amar (Esteban Crespo, 2017) comienza con una escena ciertamente transgresiva con respecto a las prácticas más normalizadas: Carlos (Pol Monen) regala a Laura (María Pedraza) el pene de plástico con el que ella lo sodomizará a continuación. La propuesta resulta arriesgada e innovadora, sobre todo si tenemos en cuenta que en este caso se trata de permitir la realización de una fantasía femenina, pues es Carlos quien ha tenido que vencer sus reticencias para complacer a su joven amante. De nuevo el encuadre y otros aspectos de la imagen -la luz cegadora de estas primeras escenas del film- contribuirán a aligerar, incluso a desrealizar, el contenido sexual de esta secuencia, así como de las que recogen los otros encuentros eróticos de los protagonistas. ${ }^{20}$

Insistimos en que lo que nos parece particularmente llamativo es el contraste entre el peso que las relaciones sexuales tienen en estos filmes y la representación de las mismas, que se esfuerza por interponer obstáculos a la mirada del espectador. No queremos con esto llegar a conclusiones precipitadas, otros filmes prefieren hacer desaparecer esas barreras, reclamándose "antielípticos" y "antimetafóricos" (Gubern 2005: 29) en lo que respecta a la representación de los actos sexuales.

Tal vez no deje de tener su interés el que dos de los filmes de contenido sexual más explícito de estos últimos diez años hayan sido dirigidos por dos directores cuya carrera se consolidó a finales del siglo pasado y comienzos de este. En efecto, Mapa de los sonidos de Tokio (2009), de Isabel Coixet y Habitación en Roma (2010), de Julio Médem, se desmarcan de las películas que hemos citado

20 Este mismo año, François Ozon optaba por un encuadre muy diferente para otra escena de sodomía con dildo, en L'amant double. Si bien no tenemos visibilidad directa de los genitales, sí se incluyen planos de los cuerpos desnudos de los actores -Marine Vacth y Jérémie Renier-. 
hasta ahora, viniendo a completar las listas de los filmes españoles de mayor explicitud sexual de este siglo. Los dos ofrecen secuencias en las que el acto sexual no se integra simplemente en un relato, sino que se convierte en un verdadero "espectáculo visual" (Servois 2009: 48).

Es posible establecer un paralelismo entre los filmes que nos interesan y las tipologías propias de la producción pornográfica más paradigmática (WiIliams 1989: 174 y ss.; Servois 2009: 48 y ss.). Así, podríamos considerar el film de Médem como un ejemplo de "pornotopía platónica", que podemos entender como la solución de separación que ofrecen aquellos filmes que recrean un mundo utópico, sin antagonismos sociales ni políticos, un lugar fuera del mundo real (Servois 2009: 55), equiparable al espacio protector que crea Julio Médem en su película. En efecto, si los antagonismos que determinan la vida y las trayectorias sexuales de las dos protagonistas son reseñados en el film, en la habitación del hotel toma forma un espacio-tiempo particular en el que estos se anulan, permitiendo una reinvención de los personajes a través de la fabulación -las historias que se cuentan, cuya veracidad no es garantizada- y de la libertad sexual.

¿Responden los encuadres al principio de "visibilidad óptima" que había postulado Román Gubern (2005: 19) para el cine pornográfico? La desnudez se impone en casi todo el film, y diversos momentos del metraje ofrecen ejemplos de fragmentación corporal, una parcelación "que ha llegado a ser canónica en el género" (Gubern 2005: 30), si bien es cierto que no hallamos primeros planos de los genitales, lo que parece legitimar a cierta crítica a calificar el film de "soft porn de alto standing para un público cultureta" (Calvo s.a.: s.p.). "Cursi", "kitsch" fueron otras calificaciones para una obra que no llegó a convencer a la prensa en su día (Iglesias 2010; Costa 2010), aunque algún trabajo académico posterior (González 2011) resaltara la importancia del mismo para visibilizar una sexualidad, la lesbiana, todavía escasamente representada en la producción cultural.

Tampoco convenció a la crítica el film de Isabel Coixet que aquí nos interesa. Se subrayó el manierismo y afectación de la nueva propuesta cosmopolita de la catalana, así como la inadecuación del castin (Boyero 2009; Costa y Sánchez, 2009). Aunque también aquí encontramos el cronotopo sexual de la habitación de hotel, en ella se reúnen ahora los amantes regularmente, y resulta más difícil aislar esos momentos de sus vidas cotidianas. Podemos considerar en este caso el tratamiento de las escenas sexuales de "pornotopía integrada" (Servois 2009: 61), siendo evidente el esfuerzo por integrar los encuentros sexuales en una trama narrativa con elementos de thriller y cine negro. De nuevo la espectacularización es un componente fundamental de la representación sexual en este caso, incluso si en algún momento podemos entenderla como denuncia de la objetualización de la mujer, presentada como bandeja de sushi en unos planos de cuidada composición, aspecto asimismo remarcable en las secuencias que recogen los momentos de intimidad entre Ryu (Rinko Kikuchi) y David (Sergi López), que obedecen a una marcada estetización. La duración y repetición de estos encuentros justifica el que los equiparemos con cierta modalidad de pornotopía, aunque, más todavía que en el film de Médem, podemos identifi- 
car la representación de la sexualidad con la del "erotismo del cine tradicional, polarizado en la fijación del deseo en el rostro, el busto femenino y las piernas" (Gubern 2005: 30), prefiriéndose en estos casos los medios planos a los planos de detalle que contribuyen a esa parcelación a la que hacíamos antes referencia.

Ambos filmes se alejan pues del componente genital que sí aparece en otros filmes de autor actuales -L'inconnu du lac (Alain Guiraudie, 2013), Love (Gaspar Noé, 2015) - y que no había temido introducir el propio Médem en Lucía y el sexo. Su extrema estetización (decorados, composición del plano, trabajo de luz y color, limpidez de la imagen), distancia por otra parte estas propuestas de otras más naturalistas y explícitas que habían reavivado "el sueño del crossover" (Williams 2009: s.p.), convirtiendo a los filmes de Médem y Coixet en una reactualización de un cine erótico cuyos ejemplos no son numerosos en el cine español más actual pero en el que sí son visibles algunos aspectos que ya nos han interesado, como la voluntad de normalización de otras orientaciones más allá de la heterosexualidad normativa (las lesbianas en el filme de Médem) o la presencia de otras prácticas sexuales (el cunilingus en el filme de Coixet).

Pese al contenido sexual de algunos filmes, tenemos pues dificultades para identificar en la cinematografía española películas que se correspondan con ese crossover que supone una intersección entre el hardcore y el film de autor (Williams 2009). Claro que no pretendemos haber agotado todos los films de estos últimos diez años, y sin duda hemos omitido alguno que hubiera sido interesante para nuestro estudio, pero incluso en este caso no podemos hablar de una tendencia, como sí encontramos desde finales del siglo anterior en los cines estadounidense o francés. ${ }^{21}$ Nos vamos acercando así al final de este recorrido, pero antes querríamos ocuparnos de aquellas películas que convierten la producción de imágenes pornográficas en parte de sus argumentos. En las páginas que siguen tendremos ocasión de ver que estos filmes muestran la crisis esencial que vive esta industria en el nuevo siglo.

\section{4. ¿RODAMOS UNA PELI PORNO?}

En 2006, un artículo de El País cifraba las ganancias del "otro Hollywood" y se hacía eco de "El gran negocio del porno". Tres años después, sin embargo, dos de sus grandes representantes, Joe Francis y Larry Flint, solicitaban ayuda económica al congreso americano (El Mundo 2009), considerando que la industria pornográfica merecía el mismo apoyo que estaban recibiendo en ese momento otras industrias afectadas por lo que podemos considerar un auténtico tsunami financiero. Si la demanda de los magnates parecía más cercana a una estrategia de márquetin, otras voces se alzaron a partir de entonces para llamar la atención acerca de la situación del sector, entre ellas la ex actriz porno y actual directora francesa Ovidie, quien realiza un análisis de la cuestión en Pornocratie, les nouvelles multinationales du sexe (2017). La realizadora pone en paralelo la crisis de

\footnotetext{
${ }^{21}$ Pese a ser de 2013, no hemos podido visionar La jungla interior (Juan Barrero) antes de cerrar estas líneas. El film nos ha sido señalado por lo explícito de alguna escena sexual.
} 
la industria pornográfica y la financiera, que coinciden en fechas, y al hacerlo llama la atención acerca de la desaparición de la primera tal como ella la conoció.

Asistimos, en efecto, a una radical mutación en ese sector, equiparable a la sufrida por la industria musical y que se debe sobre todo a las transformaciones aportadas por la revolución digital: "desmaterialización",22 acceso y gratuidad de los contenidos, prosumo ${ }^{23}$... Elementos que vienen a transformar el rol de todos los participantes en la cadena de comunicación pornográfica, y que determinan el establecimiento de relaciones particulares en tiempos de crisis económica. En efecto, si sería reductor y falso establecer una línea directa entre crisis financiera y crisis de la industria pornográfica, lo cierto es que la primera determina comportamientos que influyen decisivamente en la segunda, y así lo reconocen los actores de la industria pornográfica -la antigua y la nueva-, que se convierte en salida para algunos (sobre todo para algunas) que se han quedado sin otras oportunidades en tiempos de crisis. ${ }^{24}$

El cine español refleja esas circunstancias, que explicitan, por otro lado, la particular relación que se establece entre las diferentes generaciones y la producción y reproducción de imágenes. No ha esperado, sin embargo, el celuloide a la crisis financiera, también le ha interesado tematizar otros momentos de ese sector de la industria sexual: recién estrenado el siglo, Pablo Berger rodaba Torremolinos 73 (2003), film en el que se evocaba con humor y profundidad la transformación de un vendedor de enciclopedias en director de pornografía amateur, ante la crisis -otra más- de su sector y antes de descubrirse una pasión cinéfila que acortará una carrera prometedora en la pornografía. Se recrea en el film de Berger un momento particular de la industria, a comienzos de los años setenta en España, cuando todavía la censura era efectiva. Aunque esa circunstancia convierte en particular el caso español, lo cierto es que en ese momento la industria pornográfica audiovisual, también en otras latitudes, estaba en sus comienzos, y que estos no eran tan diferentes de los que vemos en el filme de Berger. Así reseña Lucía Egaña la situación:

Aunque el porno fue ilegal en el mundo occidental hasta finales de los 60 's, en su lugar se producían películas documentales, de filiación médica, y de pedagogía sexual (de domesticación (hetero)sexual), donde las diversas posiciones ilustraban los prolegómenos de la reproducción humana (y de la reproducción de roles, hábitos y relaciones humanas). (Egaña 2009: s.p.)

\footnotetext{
22 Ponemos el término entre comillas porque es bien sabido hoy que esa desmaterialización es mera ilusión: los datos que nos permiten prescindir de ciertos objetos, como los CD o los DVD, se materializan no solo en los dispositivos de registro y reproducción que se multiplican -a la convergencia de dispositivos se opone la obsolescencia programada- sino también en inmensos data centers situados particularmente en lugares con bajas temperaturas.

23 La cultura 2.0 se apropió con entusiasmo de un término propuesto en 1979 para dar cuenta del consumidor "del mañana", el de la "tercera ola", de la fase post-industrial, el que "comienza a cerrar la brecha histórica abierta entre productor y consumidor, dando origen a la economía del 'prosumidor'" (Toffler 1981: 10).

24 El artículo de Daniel Verdú (2015: s.p.) nos cuenta, por ejemplo, como "[l]a crisis propicia el auge de páginas de sexo anónimas retrasmitido en directo [y l]a industria del porno absorbe la fórmula".
} 
Hace patente, de ese modo, la investigadora una "relación 'biográfica' del porno con la pedagogía, la medicina y las tecnologías biofarmacológicas, [lo que] plantea que discursos con respaldo científico resultan definitorios para las prácticas de género, y un lugar de control social infiltrado discretamente en la representación del sexo", ${ }^{25}$ algo que el film pone de manifiesto al evidenciar la manipulación que rodea a los personajes y, más precisamente, la estructura patriarcal que marca sus límites de acción. Pero también se hace visible la relación de conveniencia entre crisis económica y pornografía, que volveremos a encontrar una década más tarde en uno de los filmes más emblemáticos de este último "cine de la crisis".

El argumento de Hermosa juventud (Jaime Rosales, 2014) no gira en torno a la industria pornográfica, la película muestra sin embargo claramente el aspecto tentacular que esta ha desarrollado en el siglo XXI, en plena recesión. El motivo de la pornografía enmarca el film de Jaime Rosales: no han pasado trece minutos de metraje cuando vemos a la pareja protagonista en la entrevista previa al rodaje de un film pornográfico; sin ropa y posicionándose ante una cámara abandonamos a Natalia, en el último plano de Hermosa juventud. Mucho ha sucedido entre ambas escenas, y ello hace que el final sea más desesperanzador. En la primera experiencia, el dinero aparece como motivación esencial, pero también se evoca una parte de fantasía (masculina) a la que obedece el haber cedido a la tentación del dinero fácil. El final del film elimina la ambigüedad que planeaba sobre ese rodaje, es un trabajo estable lo que busca Natalia, y lo que la lleva a Alemania, como a tantos españoles que han dejado su país en tiempos de crisis. Su desnudo final ante las cámaras subraya, pues, el fracaso de los personajes en un mundo que les niega oportunidades o se las pone a precio muy caro. El final se carga de intensidad en contraste con el recuerdo del primer rodaje, cobran así nuevos significados la soledad de Natalia, que antes estaba acompañada; su alemán chapurreado y la vulgaridad de los comentarios del presentador. El pesimismo se evidencia aún más al comparar el film con el que acabamos de comentar de Pablo Berger: si atendemos a los momentos en los que Carmen (Candela Peña, 00:20:41 y siguientes) y Natalia (Ingrid García Johnson, 00:17:07 y siguientes) se desvisten ante un extraño en Torremolinos 73 y Hermosa juventud respectivamente, los gestos tímidos y pudorosos de la tardofranquista se oponen a la desenvoltura de la joven perteneciente a una generación habituada a las cámaras, como nos lo muestran las numerosas escenas en las que la pantalla cinematográfica se fusiona con la del ordenador o la del teléfono para dar cuenta de las conexiones por Skype o WhatsApp o mostrar alguna de las numerosas fotos que ritman la vida de esta generación hiperconectada. Sin embargo, en este caso, las cámaras permitirán a Carmen realizar su proyecto,

\footnotetext{
25 Los años desnudos. Clasificada S (Félix Sabroso y Dunia Ayuso, 2011) da un salto de poco años para retratar a un país ávido de destape. Véase Seguin Vergara (2015), quien se acerca a la obra de Jesús Franco para cuestionar el paso del cine $S$ al X en España, no sin antes ofrecernos ciertas precisiones en cuanto a terminología y legislación (71-73). Alejandro Melero Salvador cruza el estudio de la Sexploitation con el de la representación lésbica, y define la figura de la "heterolesbiana" presente en estos filmes (2010: 79-126).
} 
mientras que para Natalia marcarán episodios recurrentes en la continua lucha por la supervivencia.

El realismo documental de Hermosa juventud se consigue gracias a estrategias como la improvisación en algunas escenas o el rodaje en espacios reales; en lo que se refiere a las escenas que acabamos de comentar, es además importante el haber contado con la colaboración de Ignacio Allende "Torbe", quien era ya entonces el "rey del porno español" (Verdú 2016), antes de convertirse en sinónimo de la cara más oscura de ese negocio, al ser imputado por delitos de abusos sexuales, pornografía infantil y trata de seres humanos. Pronto empezarían a hacerse públicos detalles de unos rodajes que parecían lejos de las experiencias que eran habituales en el negocio dos décadas, e incluso una década antes, pareciendo confirmarse de esa manera los análisis que realizan de la pornografía actual conocedores del sector, quienes llaman la atención acerca de la transformación de la industria pornográfica y la imposición de prácticas cada vez más extremas para atraer a un público ávido de nuevas experiencias. ${ }^{26}$

Es tal vez un filme que tematiza la pornografía casi sin apenas proponérselo, No lo llames amor... Llámalo X, película de 2011 dirigida por Oriol Capel, el que mejor representa el fin de la industria pornográfica "tradicional", que coincide con la extensión del dominio de lo pornográfico fuera de los límites que se consideraba le estaban asignados. Se trata del único largometraje, hasta ahora, de quien está sin embargo muy presente en el panorama audiovisual español, como guionista de algunas de las series televisivas de más éxito -7 vidas (Globomedia, Telecinco, 1999-2006), Aída (Globomedia, Telecinco, 2005-2014)- y de algunos de los filmes más taquilleros de los últimos años -Que se mueran los feos (2010), Perdiendo el Norte (2015) ${ }^{27}$-. La referencia a Por qué lo llaman amor cuando quieren decir sexo (Manuel Gómez Pereira, 1993) se impone desde el título de una película que tiene tanto, o más, de televisiva que de cinematográfica. ${ }^{28}$

El largometraje de Oriol Capel narra la vuelta al mundo del cine pornográfico de quien lleva veinte años alejado de él. El alzamiento nacional, así se titula su nuevo y ambicioso proyecto: una película pornográfica sobre la guerra civil española -"Un auténtico disparate" (Bonet Mojica 2011: s.p.)-. Si parece que el proyecto no debería dejar a nadie indiferente, lo cierto es que la película que se rueda dentro de la película no es esperada por nadie y nadie llegará a verla, quedando bien claro que la época para ese tipo de cine pasó hace mucho tiempo.

\footnotetext{
26 Algo que coinciden en señalar dos figuras tan diferentes como Ovidie, a la que ya nos hemos referido, y la investigadora Michela Marzano, que se distingue por sus posiciones antipornografía, contrariamente a la antigua estrella de la industria pornográfica, convertida hoy en realizadora de porno chic. Ya en 2003 la investigadora (Marzano 2003a) advierte acerca de lo extremo de las nuevas prácticas en la industria.

27 Los dos filmes fueron dirigidos por Nacho G. Velilla, quien también realizó labores de dirección en las series que hemos mencionado.

${ }^{28}$ Encontramos asimismo un plantel de actores recurrente, que se convierte en indicativo de este tipo de cine televisivo que goza del favor de un público que parece agradecer reencontrarse en la sala con las caras que lo acompañan en su salón, pero también con un lenguaje audiovisual muy próximo al de la sitcom. El film de Capel no consiguió sin embargo el éxito en taquilla que este cóctel de elementos anunciaba.
} 
A pesar de que el propio director afirme que el motivo de la pornografía le interesaba sobre todo como mero trasfondo de las historias de amor que se desarrollan en el filme (Fotogramas 2011: s.p.), este, desde su vertiente paródica, termina convirtiéndose en un canto del cisne de la industria pornográfica tal como la conocimos en el siglo xx, antes de que se diera el paso del sexo al cibersexo, y del VHS al ratón y al clic.

Precisamente "Aaaah..., clic, hmmm!" titulan Philippe Azoury y Emmanuelle Richard un artículo aparecido hace algo más de una década y en el que sintetizan la evolución del mercado de la pornografía. Al hacerlo ponen en evidencia -no son los únicos (Servois 2009) - la relación de ese sector con otros de la industria mediática contemporánea, como la telerrealidad. Esta modalidad televisiva y la evolución de la industria pornográfica aportan dos ejemplos de una muy contemporánea utopía de transparencia absoluta, que pasa por la ilusión de saciar un insaciable voyerismo y que debe tanto a profesionales como a amateurs (cualquiera que practique sexo delante de una cámara conectada). Demonios tus ojos (Pedro Aguilera, 2017) convierte estas cuestiones en motor narrativo. "Incesto fatal en tiempos de YouTube", "un drama erótico sobre la pulsión voyerística" (Iglesias 2017) son sin duda acertados sintagmas para describir el film, en el que un director de cine se obsesiona con su hermana tras haber visto en Internet un vídeo pornográfico amateur protagonizado por ella. ${ }^{29}$ Cuando Oliver (Julio Perillán) encuentra las imágenes en las que reconoce a su hermana (Ivana Baquero), ello se debe a la mera casualidad, y ni siquiera podemos saber entonces si nos hallamos ante imágenes grabadas intencionalmente para su explotación en línea o si se trata de imágenes "robadas": perdidas en la web, recuperadas desde cualquier ordenador y dispositivo móvil, vienen a dar fe de una fragmentación y desnarrativización características de las nuevas modalidades de registro y difusión de imágenes, que se habrían convertido en la marca de fábrica de la actual industria pornográfica, estableciendo un puente con la pornografía audiovisual de los primeros tiempos (Mendíbil Blanco, García García y García Guardia 2017: 156).

\section{FINAL}

¿Vive nuestra sociedad al ritmo de una "orgía permanente" en la que la producción cultural actúa como forma elemental de la excitación colectiva? (Attimonelli y Susca 2017: 27 y 33). ¿Nos hallamos en una "era farmacopornográfica" en la que el sexo y la sexualidad se han convertido en el centro de la actividad política y económica? (Preciado 2013: 26). Reflexiones de este tipo han constituido un punto de arranque para nuestra observación del cine español de esta última década. Nos parecía pertinente cuestionar la existencia de un discurso pornográfico en

\footnotetext{
${ }^{29}$ El film contiene, más allá de lo pornográfico, una tematización del dispositivo fílmico y espectatorial cuyo tratamiento ha dividido a la crítica en el momento de su estreno -(Costa 2017, Iglesias 2017, Weinrichter 2017)-. Estas cuestiones y las referencias a Zulueta, Villaronga o Bigas Luna, Powell o Hitckcock aseguran que el film sea objeto de más críticas y exégesis en un próximo futuro.
} 
el cine español en un momento en el que la expresión en ciertos medios puede llevar a pensar que la cultura se habría transformado en "pornocultura" (Attimonelli y Susca 2017).

Las películas españolas de esta última década reflejan las vivencias de personajes que se encuentran en un cruce de crisis, económicas y sociales, que han cambiado radicalmente las certezas que parecían haberse establecido a finales del siglo pasado. Sus maneras de vivir el sexo se ven modificadas sin duda por esas circunstancias, que los alienan de su propia sexualidad y/o los invitan a ampliar sus perspectivas al respecto. Nuevos roles y nuevas imágenes sexuales se incluyen en películas que quieren favorecer la normalización de orientaciones y prácticas contrarias a las hegemónicas. Es significativa en este sentido su presencia en obras dirigidas a una amplia audiencia, lejos de los circuitos marginales a los que estaban reservadas en otros momentos. Pero los filmes que dan cuenta de esta liberalización de los usos amorosos y sexuales resultan en cierta manera paradójicos, pues cuanto más parecen emanciparse los personajes en cuestiones libidinales, menos sexo se muestra en las pantallas.

Nos atrevemos, pues, a decir que, de modo general, estamos bien lejos de un discurso pornográfico en el cine español, aunque de manera puntual algunas películas asuman una representación de la sexualidad que las acerca a las imágenes pornográficas. ¿Enfría las pantallas la (supuesta) falta de tabú en torno al sexo? ¿Se ha establecido un tácito reparto de representaciones entre los tubes para Internet y los films que se consideran cinematográficos? En cuanto al primer aspecto, la voluntad de ciertos actores de no desnudarse en la pantalla, por miedo a la reacción del público, o la dificultad que acompaña la reproducción de imágenes de explícito contenido sexual fuera del aún estigmatizado ámbito de la pornografía industrial son indicadores de que imagen pornográfica y tabú siguen haciendo buena pareja. No es sin duda ajena a estas cuestiones la importante financiación por parte de cadenas de televisión generalistas (Atresmedia y Telecinco), que conocen bien los límites de representación aceptables para su público.

La aparente contradicción que hemos señalado se corresponde con la naturaleza paradójica que reconoce Gilles Lipovetsky como característica de los tiempos hipermodernos. En cuestiones sexuales, de comportamientos y de representación, llama la atención el sociólogo acerca de la combinación de una "inflacción orgiástica" en los medios -haciendo referencia sobre todo a la accesibilidad a la pornografía online- con un "hedonismo temperado" en los comportamientos, que serían poco transgresivos y excesivos, caracterizados por una "moderación libidinal" (Lipovetsky 2006: 219-225) que, nos atrevemos a aventurar, se plasma en el cine generalista; es asimismo más que moderado el contagio que este experimenta de las formas pornográficas, con las que mantiene una relación no tan diferente a la existente en otros momentos del ecosistema audiovisual. La industria pornográfica ha conocido una verdadera revolución, como la está conociendo, asimismo, toda industria cultural, pero en esa transformación la pornografía sigue siendo pornografía: se consume (masivamente) en privado y sigue siendo señalada como nociva para la sociedad, sobre todo 
a partir de sus efectos en la juventud (Lupo 2015: s.p.) y en los roles de género, llegando a destacarse su influencia en la violencia doméstica (Audureau y Leloup 2017: s.p.). El interés que la investigación universitaria muestra por ella no ha hecho desaparecer el estigma que le está asociado, ello es evidente en el revuelo que provocan aquellos filmes que adoptan sus códigos y en aquellos otros que optan por alejarse de sus modos de representación, evacuando imágenes de explícito contenido sexual.

En todo caso, mientras unos renuncian a las imágenes, otros las reivindican, algo que nos lleva de vuelta a esas expresiones alternativas tan necesarias, que agrupamos bajo el término de post-pornografía, y que desarrollan otros trabajos de este dosier.

\section{OBRAS CITADAS}

Aguilar Carrasco, Pilar (1998): Mujer, amor y sexo en el cine español de los 90. Madrid, Fundamentos.

- (2010): "La representación de las mujeres en las películas españolas: un análisis de contenido". En Fátima Arranz (ed.): Cine y género en España. Madrid, Cátedra, pp. 211-274.

Alfeo Álvarez, Juan Carlos; González de Garay Domínguez, Beatriz; y Rosado Millán, María Jesús (2011): "Adolescencia e identidades LGBT en el cine español. Evolución, personajes y significados", Icono 14 , vol. 9, n. ${ }^{\circ} 3$, pp. 5-54.

Allbritton, Dean (2014): "Prime risks: the politics of pain and suffering in Spanish crisis cinema", Journal of Spanhish Cultural Studies, vol. 15, accesible en <http://dx.doi.org /10.1080/14636204.2014.931663> [última visita: 15.9.2017].

Audureau, William, y Leloup, Damien (2017): "Violences faites aux femmes: Emmanuel Macron souhaite un meilleur contrôle des jeux vidéo, des réseaux sociaux et de la pornographie", Le Monde, 25 de noviembre, accesible en <http://www.lemonde. $\mathrm{fr} /$ pixels/article/2017/11/25/violences-faites-aux-femmes-emmanuel-macron-souhaite-un-meilleur-controle-des-jeux-video-des-reseaux-sociaux-et-de-la-pornographie_5220411_4408996.html> [última visita: 6.12.2017].

Ares, Loreto, y Pedraz Poza, Sara A. (2011): "Sexo, poder y cine. Relaciones de poder y representaciones sexuales en los nuevos relatos pornográficos", Icono 14, vol. 9, n. ${ }^{\circ}$ 3, pp. 98-119.

Arranz, Fátima (2010): "La igualdad de género en la práctica cinematográfica española". En Fátima Arranz (ed.): Cine y género en España. Madrid, Cátedra, pp. 17-68.

Attimonelli, Claudia, y Susca, Vincenzo (2017): Pornoculture. Voyage au bout de la chair [2016, en italiano]. Montréal, Liber.

Azoury, Philippe, y Richard, Emmanuelle (2006) : "Aaaah..., clic, hmmm !", Libération, 8 de julio, accesible en <http://www.liberation.fr/ecrans/2006/07/08/aaaah-clichmmm_45197? page=article > [última visita: 15.9.2017].

Barroso, Miguel Ángel (2001): Cine erótico en cien jornadas. Madrid, Jaguar.

Bonet Mojica, Lluís (2011): "No lo llames amor, llámalo X: Todos con Franco, Jess, claro", La Vanguardia, 6 de mayo, accesible en <http://www.lavanguardia.com/ 
cine/20110506/54150913461/no-lo-Ilames-amor-llamalo-x-todos-con-francojess-claro.html> [última visita: 15.9.2017].

Boyero, Carlos (2009): "Último tango en Tokio", El País, 24 de mayo, accesible en <https:// elpais.com/diario/2009/05/24/cultura/1243116002_850215.html> [última visita: 15.9.2017].

Calvo, Alejandro (2010): "Habitación en Roma", Sensacine, accesible en <http://www.sensacine.com/peliculas/pelicula-141302/criticas-prensa/\#pressreview19729427> [última visita: 15.9 .2017$]$.

CIMA (2017): Informe CIMA 2016. La representatividad de las mujeres en el sector cinematográfico español, accesible en <http://cimamentoring.com/informe-anual-2016/> [última visita: 15.9.2017].

Costa, Jordi (2010): "Habitación en Roma", Fotogramas, accesible en <http://www.fotogramas.es/Peliculas/Habitacion-en-Roma> [última visita: 15.9.2017].

_ (2017): "Una mirada a los límites", El País, 12 de mayo, accesible en <https://elpais.com/ cultura/2017/05/11/actualidad/1494504377_119087.html> [última visita: 15.9.2017].

_ y Sánchez, Sergi (2009): "Mapa de los sonidos de Tokio", Fotogramas, accesible en <http://www.fotogramas.es/Peliculas/Mapa-de-los-sonidos-de-Tokio> [última visita: 15.9.2017].

Cristobal, Ramiro (2010): La homosexualidad en el cine. Madrid, Ediciones irreverentes.

Del Corral, Pedro (2017): "Imagina ser directora de cine. Solo un 20\% de ellas lo consigue", El Mundo, 8 de marzo, accesible en <http://www.elmundo.es/cultura/2017/03/08/5 8bf09c646163ff5208b4576.html> [última visita: 15.9.2017].

Egaña, Lucía (2009): "La pornografía como tecnología de género. Del porno convencional al postporno. Apuntes freestyle", La Fuga, edición 9, accesible en <http://www.lafuga.cl/la-pornografia-como-tecnologia-de-genero/273> [última visita: 15.9.2017].

El blog de cine español (2013): "Ránking: las diez películas españolas más eróticas del siglo xxı", El Blog de Cine Español, accesible en <http://www.elblogdecineespanol. com/?p=12008> [última visita: 15.9.2017].

El Mundo (2009): "La industria del porno de EE.UU pide ayuda para afrontar la crisis", El Mundo, 8 de enero, accesible en <http://www.elmundo.es/mundodinero/2009/01/08/ economia/1231374682.html> [última visita: 15.9.2017].

— (2015): "El director de Playboy tras eliminar los desnudos: 'Ya es algo pasado de moda'", El Mundo, 11 de noviembre, accesible en <http://www.elmundo.es/televisi on/2015/11/11/5642c476ca4741634e8b463b.html> [última visita: 15.9.2017].

El País (2006): "El gran negocio del 'porno'", El País, 26 de noviembre, accesible en <https:// elpais.com/diario/2006/11/26/domingo/1164516755_850215.html> [última visita: 15.9.2017].

_ (2017): "Playboy recupera los desnudos en su revista", El País, 14 de febrero, accesible en <https://elpais.com/elpais/2017/02/13/estilo/1487014622_897717.html> [última visita: 15.9 .2017$]$.

Fernández Porta, Eloy (2012): €®0\$ [2010]. Barcelona, Anagrama.

Filmaffinity (s.a.): "Castillos de cartón", Filmaffinity, accesible en <https://www.filmaffinity. com/es/film726002.html> [última visita: 15.9.2017]. 
Fotogramas (2011): "Estreno No lo llames amor... llámalo X", Fotogramas, 3 de mayo, accesible en <http://www.fotogramas.es/Peliculas/No-lo-llames-amor-llamalo-X/ Estreno-No-lo-Ilames-amor-Ilamalo-X> [última visita: 15.9.2017].

Freixas, Ramon, y Bassa, Joan (2005): Cine, erotismo y espectáculo. Barcelona, Paidós.

- (2000): El sexo en el cine y el cine de sexo. Barcelona, Paidós.

Fuentefría Rodríguez, David (2017): "PorNo Future: estética del totalitarismo en la bilogía 'Latex' y 'Shock', de Michael Ninn", Fotocinema, n. ${ }^{\circ} 15$, pp.179-201.

García, Álvaro (2009): "Sé lo que es cuando lo veo. Breve introducción a la imagen pornográfica", La Fuga, edición 9, accesible en <http://www.lafuga.cl/se-lo-que-escuando-lo-veo/262> [última visita: 15.10.2017].

García García, Francisco, y Arroyo Fernández, Miguel (2011): “Discursos sobre la sexualidad en el cine. Presentación", Icono 14, vol. 9, n. 3, pp. 1-4.

García Rodríguez, Javier (2008): El celuloide rosa. Barcelona, Ediciones de La Tempestad.

González, Clarissa (2011): "Visibilidad y diversidad lésbica en el cine español. Cuatro películas de la última década", Icono 14, vol. 9, n. ${ }^{\circ}$, pp. 221-255.

Gubern, Román (2005): La imagen pornográfica y otras perversiones ópticas. Barcelona, Anagrama.

Iglesias, Eulàlia (2010): "Los excesos del amor", Público, 7 de mayo, accesible en <http:// www.publico.es/culturas/excesos-del-amor.html> [última visita: 15.9.2017].

Iglesias, Eulàlia (2017), "Demonios tus ojos: incesto fatal en tiempos de YouTube", El Confidencial, 12 de mayo, accesible en <https://www.elconfidencial.com/cultura/ cine/2017-05-12/demonios-tus-ojos-estreno_1381156/> [última visita: 15.9.2017].

Kourelou, Olga; Liz, Mariana; Vidal, Belén (2014), "Crisis and creativity: The new cinemas of Portugal, Greece and Spain", New Cinemas, vol. 12, n. ${ }^{\circ} 1-2$, pp. 133-151.

Lipovetsky, Gilles (2006): Le bonheur paradoxal. Essai sur la société d'hyperconsommation. París, Gallimard.

Lupo, Carolina (2015): "La pornografía en Internet", Nuestro tiempo, n. 696, accesible en <http://www.unav.es/nuestrotiempo/es/temas/pornografia-internet> [última visita: 15.9.2017].

Marzano, Michela (2003a): "La nouvelle pornographie et l'escalade des pratiques: corps, violence et réalité", Cités, vol. 3, n. 15, pp. 17-29.

- (2003b): La pornographie ou l'épuisement du désir. París, Buchet Chastel.

Melero Salvador, Alejandro (2010): Placeres ocultos. Gays y lesbianas en el cine español de la transición. Madrid, Notorious Ediciones.

Mendíbil Blanco, Álex; García García, Francisco; y García Guardia, María Luisa (2017): "Narratología porno. Una lectura semiótica de Tras la puerta verde", Fotocinema, n. ${ }^{\circ} 15$, pp. $155-177$.

Mira, Alberto (2008): Miradas insumisas. Gays y lesbianas en el cine. Barcelona/Madrid, Editorial Egales.

Montero, Laureano (2014): Le cinéma d'Eloy de la Iglesia: marginalité et transgression, tesis doctoral inédita, Université de Bourgogne Franche-Comté (Dijon), accesible en <https://tel.archives-ouvertes.fr/tel-01137787/document> [última visita: 15.9.2017].

Moral, Pedro (2016): "¿Hay un lugar para el erotismo en el cine?", Cinemanía, 4 de septiembre, accesible en <http://cinemania.elmundo.es/noticias/hay-un-lugar-parael-erotismo-en-el-cine/> [última visita: 15.9.2017]. 
Ogien, Ruwen (2008): Penser la pornographie. París, Presses Universitaires de France.

Palencia, Leandro (2011): La pantalla visible. El cine queer en 33 películas. Madrid, Editorial Popular.

Paveau, Marie-Anne (2014): Le discours pornographique. París, La Musardine.

— y Perea, François (coords.) (2015): La pornographie et ses discours. Nancy, Presses Universitaires de Nancy.

Pavés, Gonzalo, y García Gómez, Francisco (coords.) (2017): "Sexo y erotismo en el cine", dosier, Fotocinema, n. ${ }^{\circ} 15$.

Prada, Nancy (2009): "Erotismo y pornografía", La Fuga, edición 9, accesible en <http:// www.lafuga.cl/erotismo-y-pornografia/283> [última visita: 15.9.2017].

Preciado, Paul B. (2013): Testo Yonqui [2008]. Barcelona, Espasa.

Seguin Vergara, Jean-Claude (2015): "Deslizamientos progresivos del placer: del 'S' al ' $X$ ' en el cine español", Área abierta, vol. 15, n. 3, pp. 69-84.

Servois, Julien (2009): Le cinéma pornographique. París, Vrin.

Toffler, Alvin (1981): La tercera ola [1979]. Bogotá, Plaza \& Janés.

Verdú, Daniel (2016): "Yo trabajé para Torbe", El País, 17 de junio, accesible en <https:// elpais.com/ccaa/2016/06/14/catalunya/1465919624_004283.html> [última visita: 15.9.2017].

_ (2015), "La vida secreta de una webcamer", El País, 18 de marzo, accesible en <https:// politica.elpais.com/politica/2015/03/06/actualidad/1425658999_487258.html> [última visita: 15.9.2017]

Villarmea Álvarez, Iván (2016): "Rostros y espacios de austeridad en los cines ibéricos (2007-2016)". Ponencia (inédita) en XVII Forum for Iberian Studies. The Crisis in the Iberian Peninsula, 20-30 de septiembre, University of Oxford.

Viña, José Miguel (2011): "Impulso destructor. (S)experiencia perversa", Revista Icono 14, vol. 9, n. ${ }^{\circ}$, pp. 177-193.

Weinrichter, Antonio (2017): "Demonios tus ojos (**): pulsión escópica", ABC, 11 de mayo, accesible en <http://www.abc.es/play/cine/criticas/abci-critica-demonios-tusojos-201705111750_noticia.html> [última visita: 15.9.2017].

Williams, Linda (1989): Hard core: power, pleasure and te "frenzy of visible". Berkeley, University of California Press.

— (ed.) (2004): Porn Studies. Durham, Duke University Press.

— (2009): "El acto sexual en el cine", La Fuga, edición 9, accesible en <http://www.lafuga. cl/el-acto-sexual-en-el-cine/266> [última visita: 15.9.2017]. 